\title{
Interaction of Kv3 Potassium Channels and Resurgent Sodium Current Influences the Rate of Spontaneous Firing of Purkinje Neurons
}

\author{
Walther Akemann and Thomas Knöpfel \\ Laboratory for Neuronal Circuit Dynamics, RIKEN Brain Science Institute, Wako City, Saitama 351-0198, Japan
}

\begin{abstract}
Purkinje neurons spontaneously generate action potentials in the absence of synaptic drive and thereby exert a tonic, yet plastic, input to their target cells in the deep cerebellar nuclei. Purkinje neurons express two ionic currents with biophysical properties that are specialized for high-frequency firing: resurgent sodium currents and potassium currents mediated by Kv3.3. How these ionic currents determine the intrinsic activity of Purkinje neurons has only partially been understood. Purkinje neurons from mutant mice lacking Kv3.3 have a reduced rate of spontaneous firing. Dynamic-clamp recordings demonstrated that normal firing rates are rescued by inserting artificial Kv3 currents into Kv3.3 knock-out Purkinje neurons. Numerical simulations indicated that Kv3.3 increases the spontaneous firing rate via cooperation with resurgent sodium currents. We conclude that the rate of spontaneous action potential firing of Purkinje neurons is controlled by the interaction of Kv3.3 potassium currents and resurgent sodium currents.
\end{abstract}

Key words: cerebellum; potassium channels; sodium channel; spike trains; knock-out mice; Purkinje neurons

\section{Introduction}

The brain contains neurons that remain quiescent in absence of synaptic stimuli, whereas others spontaneously fire action potentials (APs) even when synaptic transmission is completely absent (Häusser et al., 2004). Spontaneous (intrinsic) spiking drives oscillatory or synchronous network behavior and is subject to activity-dependent plasticity that, on a slow timescale, regulates the intrinsic spike rate (Nelson et al., 2003; Smith and Otis, 2003). Purkinje neurons fire at an unusually high spontaneous frequency of $\sim 40 \mathrm{~Hz}$ in vivo (Granit and Phillips, 1956; Armstrong and Rawson, 1979) and at similar frequencies in slice preparations (at physiological temperature) with synaptic inputs blocked (Llinas and Sugimori, 1980; Häusser and Clark, 1997). In most spontaneously firing cell types, intrinsic regenerative activity results from interactions of mutually activating and deactivating outward and inward ion currents of different kinetics, much like the action potential itself but at a slower timescale. Previous models for Purkinje neurons emphasized the role of a resurgent sodium current that is mainly, but not exclusively, mediated by Nav1.6 sodium channel subunits (Raman et al., 1997; Khaliq et al., 2003). Resurgent sodium currents are caused by a voltagedependent open channel block that competes with, and thus lim-

Received Dec. 6, 2005; revised March 23, 2006; accepted March 24, 2006.

This work was supported by an intramural grant from the RIKEN Brain Science Institute. We thank all members of the Knöpfel Laboratory for helpful discussions and encouragement, Dr. Nathaniel Heintz (The Rockefeller University and Howard Hughes Medical Institute, New York, NY) and Dr. Rolf Joho (University of Texas Southwestern Medical (enter at Dallas, Dallas, TX) for Kv3.3 KO mice and help in transferring these mice, as well as Dr. Paul Kullmann (University of Pittsburgh School of Medicine, Pittsburgh, PA) for a tailor-made version of G-Clamp software.

Correspondence should be addressed to Dr. Thomas Knöpfel, RIKEN Brain Science Institute, Laboratory for Neuronal Circuit Dynamics, 2-1 Hirosawa, Wako City, Saitama 351-0198, Japan. E-mail: tknopfel@brain.riken.jp.

DOI:10.1523/JNEUROSCI.5204-05.2006

Copyright $\odot 2006$ Society for Neuroscience $\quad$ 0270-6474/06/264602-11\$15.00/0 its, classical inactivation (Raman and Bean, 1997; Khaliq et al., 2003; Grieco et al., 2005). Fast unblocking makes $\mathrm{Na}^{+}$channels not only quickly available for the next action potential but also generates a transient ("resurgent") inward current that contributes a depolarizing drive after each action potential (Raman and Bean, 2001). Purkinje neurons also express Kv3.3 potassium channel subunits (Goldman-Wohl et al., 1994). Kv3 subunits are found in neurons that fire at high frequencies, and, based on their biophysical properties, it has been proposed that they specifically support high-frequency firing (Erisir et al., 1999; Rudy and McBain, 2001; Lien and Jonas, 2003). For Purkinje neurons, it was reported that Kv3 channels actively dampen backpropagation of somatic sodium spikes, shape climbing fiber responses, and promote burst firing (Martina and Bean, 2003; McKay and Turner, 2004). Although the fast activation and deactivation kinetics of Kv3 channels clearly support high-frequency firing ( $\mathrm{Ra}$ man and Bean, 1999), the exact mechanism of doing so has only partially been clarified.

Here we found that the rate of spontaneous action potential firing is substantially reduced in Purkinje neurons deficient of Kv3.3 subunits. Action potentials in Kv3.3 knock-out (KO) Purkinje cells were broader, reached more positive potentials, and had a slower afterhyperpolarization (AHP). Experiments in which extracellular $\mathrm{Ca}^{2+}$ concentration was varied demonstrated that the reduced spontaneous activity of Kv3.3 KO Purkinje neurons was not simply because of enhanced calcium influx and increased activity of calcium-activated potassium channels. Normal firing rate was rescued in Kv3.3 KO Purkinje neurons when a Kv3 model conductance was reintroduced using the dynamicclamp technique. This demonstrated that changes in spontaneous firing of $\mathrm{Kv} 3.3 \mathrm{KO}$ Purkinje neurons is not attributable to alterations of other channel genes. Simulations based on a com- 
putational model of ionic currents in Purkinje neurons confirmed that the essential biophysical properties of Kv3.3 (high activation threshold, fast activation and deactivation) are sufficient to increase the rate of spontaneous action potential firing. Surprisingly, the properties of Kv3.3 alone were not sufficient to significantly facilitate spontaneous firing of Purkinje neurons in the absence of resurgent sodium currents. Thus, Kv3.3 currents and resurgent sodium currents cooperate in driving intrinsic firing of Purkinje neurons.

\section{Materials and Methods}

In this work, we used Kv3.3 KO mice along with homologous wild types (WTs) raised on a mixed 129/Sv, C57BL, and ICR genetic background. The generation and genotyping of these mice was described previously (Chan, 1997; Matsukawa et al., 2003; McMahon et al., 2004). A total of 28 Kv3.3 KO animals (postnatal day 18-27; median, 24) were used for intracellular recordings, and $13 \mathrm{Kv} 3.3 \mathrm{KO}$ animals (day 30-182; median, 42) were used for extracellular recordings. Control experiments involved four WT animals (day 23-24; median, 24) for intracellular recordings and 23 WT animals (day 25-124; median, 35) for extracellular recordings. Experimental protocols were approved by the RIKEN Experimental Animal Committee and conducted in compliance with the Guidelines for the Use of Animals in Neuroscience Research (the Society for Neuroscience).

Slice preparation. Mice were deeply anesthetized with diethyl ether or bromo-chloro-trifluoroethane and decapitated. Brains were rapidly removed from the skull and immersed in ice-cold artificial CSF (ACSF) composed of the following (in mM): $118 \mathrm{NaCl}, 3 \mathrm{KCl}, 1 \mathrm{MgCl}_{2}, 2 \mathrm{CaCl}_{2}$, $1 \mathrm{NaH}_{2} \mathrm{PO}_{4}, 25 \mathrm{NaHCO}_{3}$, and 20 D-glucose, continuously oxygenated with carbogen $\left(95 \% \mathrm{O}_{2}, 5 \% \mathrm{CO}_{2}\right)$ at $\mathrm{pH} 7.4$. A series of $280-\mu \mathrm{m}$-thick parasagittal slices were cut in a vibratome (VT1000S; Leica, Nussloch, Germany) from the brains near to the midline enclosing the cerebellar vermis. Remaining external fibers to the cerebellum were dissected, and noncerebellar tissue was removed from the sections. The sections were then recovered and stored in oxygenated ACSF at $20-24^{\circ} \mathrm{C}$ for $1-5 \mathrm{~h}$ before being used for experiments.

Single-unit recordings. For experiments, slices were transferred to a temperature-controlled recording chamber on a Leica DMLFSA microscope (Leica, Wetzlar, Germany) equipped for dual-electrode electrophysiology. The slices were superfused at $2.5 \mathrm{ml} / \mathrm{min}$ with oxygensaturated ACSF containing $20 \mu \mathrm{M}$ dioxo-nitro-tetrahydrobenzoquinoxaline-sulfonamide (NBQX) (Tocris Cookson, Bristol, UK) and 50 $\mu \mathrm{M}$ picrotoxin (Sigma, St. Louis, $\mathrm{MO}$ ). The temperature was regulated to $24 \pm 0.5^{\circ} \mathrm{C}$, except in those measurements in which the temperature was varied between 25 and $35^{\circ} \mathrm{C}$ to investigate the temperature dependence of spontaneous firing. In this case, the slices were initially equilibrated at $25^{\circ} \mathrm{C}$ and the temperature was changed in $5^{\circ} \mathrm{C}$ steps at $\sim 1^{\circ} \mathrm{C} / \mathrm{min}$. Purkinje cell bodies in the dorsal vermis were identified in the bright-field image using a $40 \times$ water-immersion objective. A borosilicate patch electrode filled with ACSF was placed in the proximity to the axon hill-hock region of the cell body. Direct cell attachment was avoided to prevent mechanical stress of the membrane. The extracellular potential was measured with an Axoclamp 200B amplifier (Molecular Devices, Sunnyvale, CA) in zero-current mode, low-pass filtered with $5 \mathrm{kHz}$ cutoff, and sampled at $10 \mathrm{kHz}$. In the case of low-calcium ACSF, the external solution contained $0.1 \mathrm{mM} \mathrm{CaCl}_{2}$ and $2.9 \mathrm{mM} \mathrm{MgCl}_{2}$, and all other concentrations were the same as in standard ACSF. The data were analyzed using Clampfit 9.2 software (Molecular Devices). Average firing rates are defined as median of the instantaneous event rate during 120 or $60 \mathrm{~s}$ recording episodes. Mean values are given as mean \pm SEM. Judgments on statistical significance are based on Student's $t$ test.

Whole-cell recordings. Patch electrodes were pulled from borosilicate glass (Hilgenberg, Malsfeld, Germany) and filled with the following (in mM): 120 K-gluconate, $9 \mathrm{KCl}, 4 \mathrm{NaCl}, 3.48 \mathrm{MgCl}_{2}, 10 \mathrm{KOH}, 10$ HEPES, 17.5 sucrose, $4 \mathrm{Na}_{2} \mathrm{ATP}$, and $0.4 \mathrm{Na}_{3} \mathrm{GTP}$, adjusted to $\mathrm{pH} 7.25$ with $\mathrm{KOH}$. The electrodes, when filled with this solution, had resistances of 3-5 M $\Omega$.

Whole-cell current-clamp recordings were performed after obtaining seal resistances $>1.5 \mathrm{G} \Omega$ using a Multiclamp $700 \mathrm{~B}$ amplifier (Molecular
Devices). Access resistance (12-22 M $\Omega$ ) was compensated by bridge adjustment. The external ASCF solution was temperature regulated to $24 \pm$ $0.5^{\circ} \mathrm{C}$. Spontaneous action potentials were recorded in zero-current mode for $120 \mathrm{~s}$ at $50 \mathrm{kHz}$ without filtering. Finally, the passive membrane response was documented by recording the voltage transients evoked by hyperpolarizing $500 \mathrm{~ms}$ current steps from a $-60 \mathrm{mV}$ holding potential. The input resistances of patched cells were in the range $70-140 \mathrm{M} \Omega$. The voltage traces were analyzed by aligning and averaging action potentials events during a $20 \mathrm{~s}$ time window in which the rate of spontaneous firing was stationary (usually within $60 \mathrm{~s}$ after switch into zero-current mode). The action potential amplitude was measured as the peak voltage with respect to the baseline level $10 \mathrm{~ms}$ before the peak of the action potential. The action potential width was evaluated at half-amplitude. The amplitude of AHP was defined as the after-spike minimum voltage with respect to the same baseline value. Maximum membrane voltage reached during action potentials and all other absolute values of membrane voltage are reported without correction for liquid junction potentials. The membrane time constant, input resistance, and whole-cell capacitance were obtained from an exponential fit to the initial voltage transient evoked by $\mathrm{a}-100 \mathrm{pA}$ current step and the maximum voltage deflection in the same transient, respectively. Grand averages were derived by averaging over mean values obtained from different neurons.

Dynamic-clamp recordings. The dynamic-clamp method was used to investigate the function of a simplified Kv3 conductance in Purkinje cell intrinsic activity. The membrane potential was measured at the soma by an intracellular patch electrode. The feedback current command was generated on a 3.2 GHz Pentium 4 computer (Dell Optiplex GX 270; Dell Computer Company, Round Rock, TX) running G-Clamp 1.2 software (developed and distributed by Paul Kullmann at the University of Pittsburgh School of Medicine, Pittsburgh, PA) under the real-time operating system LabVIEW RT-ETS (National Instruments, Austin, TX) (Kullmann et al., 2004). The computer was equipped with a 16 bit DAQ interface (NI PCI-6052E; National Instruments) to read the voltage signal from the recording amplifier and feed back the calculated current command. The feedback loop was configured using the user interface of G-Clamp under LabVIEW 7.2 (National Instruments). In each loop cycle, the virtual conductance was updated according to the recent membrane voltage, and the resulting current command was digital-to-analog converted and supplied to the command circuit of the Multiclamp 700B amplifier (Molecular Devices). A generic Kv3 model conductance was realized with binary voltage dependency (bKv3): $g(V)=G_{\max } \times H(V-$ $\left.V_{\mathrm{th}}\right)$, in which $V(t)$ denotes the membrane voltage, $V_{\text {th }}$ is the threshold potential for activation and deactivation, $G_{\max }$ is the maximum conductance, and $H$ is the Heaviside function. Activation was simulated as instantaneous, whereas deactivation was either instantaneous or evolved with a voltage-independent time constant $\tau$. In the latter case, the conductance was calculated recursively according to the following: $g(t+$ $\Delta t)=G_{\max } \times H\left(V-V_{\mathrm{th}}\right)+g(t) \times H\left(V_{\mathrm{th}}-V\right) \times(1-\Delta t / \tau)$, where $\tau$ $\gg \Delta t$, and $\Delta t$ is the time increment corresponding to one loop cycle. The resulting current was calculated from Ohm's law as $g \times\left(V-E_{\mathrm{K}}\right)$, with a potassium reversal potential $E_{\mathrm{K}}$ of $-90 \mathrm{mV}$. The dynamic clamp was performed at $48 \mathrm{kHz}$, equivalent to a cycle time $\Delta t$ of $20.8 \mu$ s with $0.5 \mu \mathrm{s}$ $\mathrm{SD}$ and $3 \mu$ s maximum jitter. In the majority of measurements, the current $(<7 \mathrm{nA})$ was injected through the recording electrode (oneelectrode configuration) with compensated electrode series resistance (bridge balance). For higher peak currents $(>7 \mathrm{nA})$, oscillations of the membrane voltage occurred as expected from limitations in series resistance compensation. To extend the range of $G_{\max }$ values, we performed additional recordings with the current passing through a second patch electrode (two-electrode configuration). In this case, both electrodes were first attached to the soma, and the whole-cell mode was established almost simultaneously. The membrane voltage and injected total current were recorded at $50 \mathrm{kHz}$ without extra filtering. The recording protocol for a set of $\mathrm{bKv} 3$ model parameters consisted of a $10 \mathrm{~s}$ baseline recording with zero-current injection, $10 \mathrm{~s}$ under dynamic-clamp conditions, followed by another $10 \mathrm{~s}$ baseline recording. This protocol was iterated for different model parameters. For each cell, the recording session was limited to a maximum of $5 \mathrm{~min}$. Depending on the amplitude of the applied conductance, in particular for $G_{\max }>50 \mathrm{nS}$, cells sometimes ceased to 


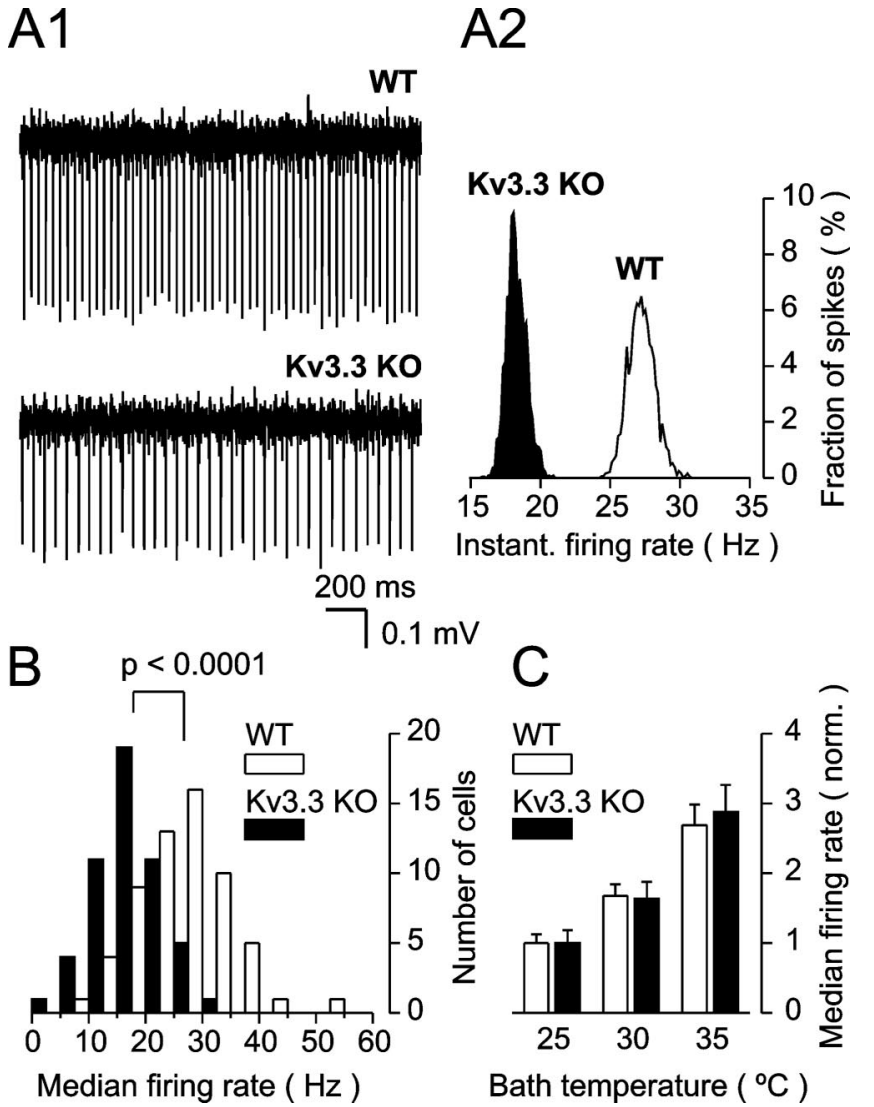

Figure 1. Reduced rate of spontaneous action potential firing in Kv3.3 KO Purkinje neurons. A1, Single-unit potentials were recorded from the cell bodies of a WT (top trace) and a Kv3.3 KO Purkinje neuron (bottom trace). The spike rates are $27.2 \pm 0.9 \mathrm{~Hz}$ (WT) and $18.3 \pm 0.8 \mathrm{~Hz}$ (Kv3.3 K0), close to the ensemble means given in $\boldsymbol{B}$. $\boldsymbol{A 2}$, Distribution of instantaneous spike frequency of cells shown in $A 1$. The histograms fit to the normal distribution with a correlation of $R>0.98$. The widths of both distributions are not different (WT, $\sigma / \mu=0.035 \pm 0.005$; $\mathrm{Kv3} .3 \mathrm{KO}, \sigma / \mu=0.038 \pm 0.008$ ). B, Median spike rates measured in WT (61 cells, 11 animals, 25-51 d old; open columns) and Kv3.3 KO (52 cells, 7 animals, $30-51 \mathrm{~d}$ old; filled columns) Purkinje neurons at $24 \pm 0.5^{\circ} \mathrm{C}$. C, Spontaneous firing rate as a function of bath temperature. Columns indicate means \pm SEM of firing rates measured at 25,30 , and $35^{\circ} \mathrm{C}\left( \pm 0.5^{\circ} \mathrm{C}\right)$ from WT (4 cells) and Kv3.3 KO (5 cells) Purkinje neurons. All measurements were performed in ACSF containing NBQX $(20 \mu \mathrm{m})$ and picrotoxin $(50 \mu \mathrm{m})$.

fire action potentials or started to fire in a nonregular mode during dynamic clamp. These recordings were excluded from the analysis. For each trace, we evaluated the mean event rates during $5 \mathrm{~s}$ periods of firing under baseline and dynamic-clamp conditions. The relative change in firing rate was then obtained as the average rate change when switching on and off the virtual conductance. Action potential waveforms were analyzed as described above. Values of $G_{\max }$ are given normalized to the measured capacitance to account for the membrane surface area of each cell.

Simulations of Purkinje neuron firing. The simulations were performed using the NEURON 5.8 simulator (Hines and Carnevale, 1997). All simulations used $5 \mu$ s time steps. The Purkinje cell model was based on the model of Khaliq, Gouwens, and Raman (Khaliq et al., 2003), referred to as the KGR model. The KGR model has been detailed by Khaliq et al. (2003) and is provided at http://senselab.med.yale.edu/senselab/modeldb. In the following, we describe modifications to the KGR model that we implemented for the purpose of the present study.

(1) To represent the two principal components of sodium current in Purkinje neurons, resurgent and nonresurgent current, two distinct sodium channels were included into the model cell. The channels were identical to the KGR models of wild-type Purkinje neurons (resurgent $\mathrm{Na}^{+}$) and Nav1.6-deficient Purkinje neurons (nonresurgent $\mathrm{Na}^{+}$) (Khaliq et al., 2003). The model of the nonresurgent current differs from

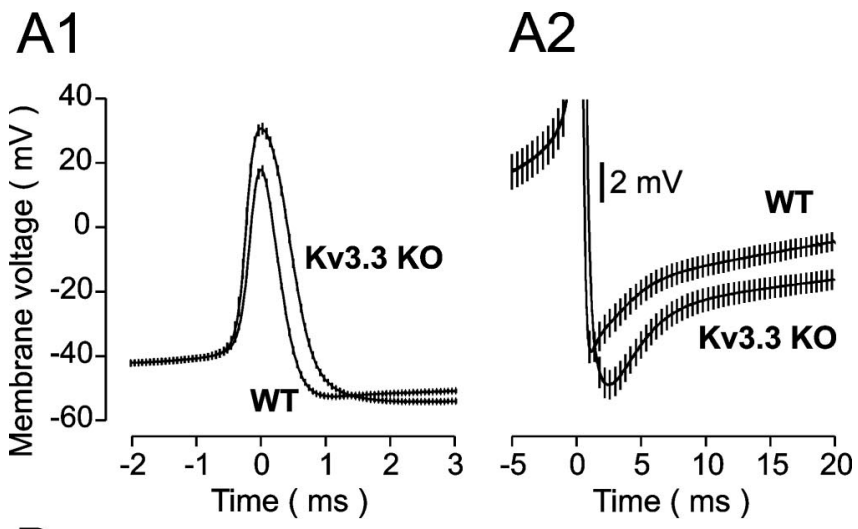

B
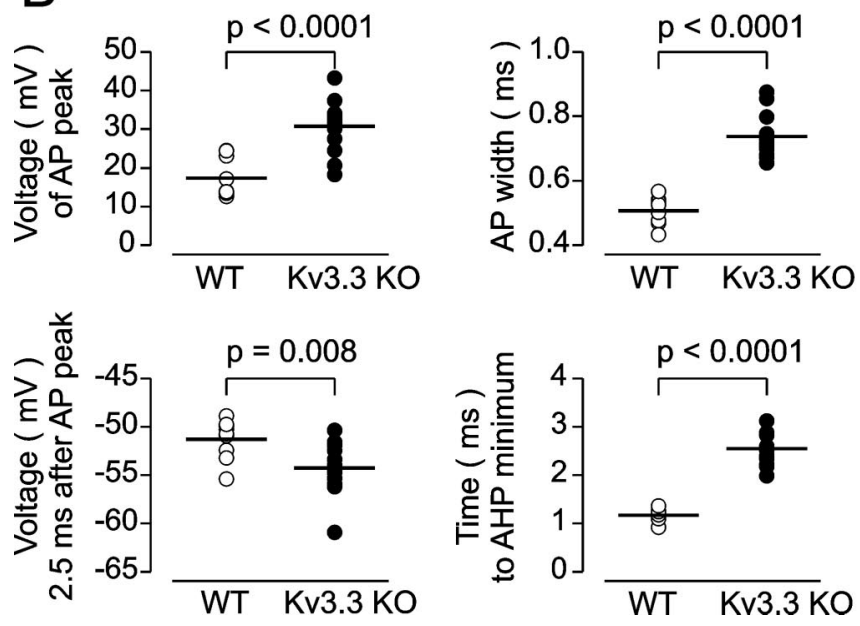

Figure 2. Waveforms of spontaneously generated action potentials in Kv3.3 K0 and WT Purkinje neurons. A1, Grand averages of action potentials recorded intracellularly from WT (9 cells, 4 animals, 23-24 dold) and Kv3.3 KO (14 cells, 4 animals, 23-27 d old) Purkinje neurons at $24 \pm 0.5^{\circ} \mathrm{C}$. Traces were aligned horizontally to the action potential peaks but not aligned vertically. Vertical bars indicate SEM over different cells. $\boldsymbol{A 2}$, Grand averages of after-spike voltage trajectory recorded in WT and $\mathrm{Kv} 3.3 \mathrm{KO}$ cells. $\boldsymbol{B}$, Summary of AP waveform parameters. Data points from individual cells are shown as open (WT) and filled (Kv3.3 KO) circles, and mean values are shown as horizontal lines. $p$ values were obtained from unpaired $t$ tests.

the model of the resurgent current by absence of the blocked state (realized by a rate constant of transition into the blocked state of $10^{-12} \mathrm{~ms}^{-1}$ compared with $1.75 \mathrm{~ms}^{-1}$ for resurgent current) and by increased openstate inactivation (with a rate constant of $2.3 \mathrm{vs} 0.75 \mathrm{~ms}^{-1}$ for the resurgent current) (Khaliq et al., 2003).

(2) The voltage-gated potassium conductances in the KGR model, $K_{\text {fast }}, K_{\text {mid }}$, and $K_{\text {slow, }}$, were replaced by a set of models, Kv1, Kv4, and $\mathrm{Kv} 3$, corresponding to molecularly defined channel entities. Lowthreshold potassium current with only very slow inactivation, as mediated by Kv1 channel members, was modeled as a $n^{4}$ Hodgkin-Huxley mechanism with forward $\left(\alpha_{n}\right)$ and backward $\left(\beta_{n}\right)$ rate constants (in $\mathrm{ms}^{-1}$ ) at $22^{\circ} \mathrm{C}$ :

$$
\begin{gathered}
\alpha_{n}(V)=0.12889 \times \exp \left(\frac{V+45}{33.91}\right) \\
\beta_{n}(V)=0.12889 \times \exp \left(-\frac{V+45}{12.42}\right)
\end{gathered}
$$

The model was adjusted to reproduce the steady-state activation curve and activation time constants reported for Kv1.1 in heterologous expression (Zerr et al., 1998) and Kv1 kinetic data for rat Purkinje neurons (McKay et al., 2005). The model features a potential of half-activation, $V_{1 / 2}$, of $-30.0 \mathrm{mV}$ and activates at $10 \mathrm{mV}$ with a time constant of $1.5 \mathrm{~ms}$. 

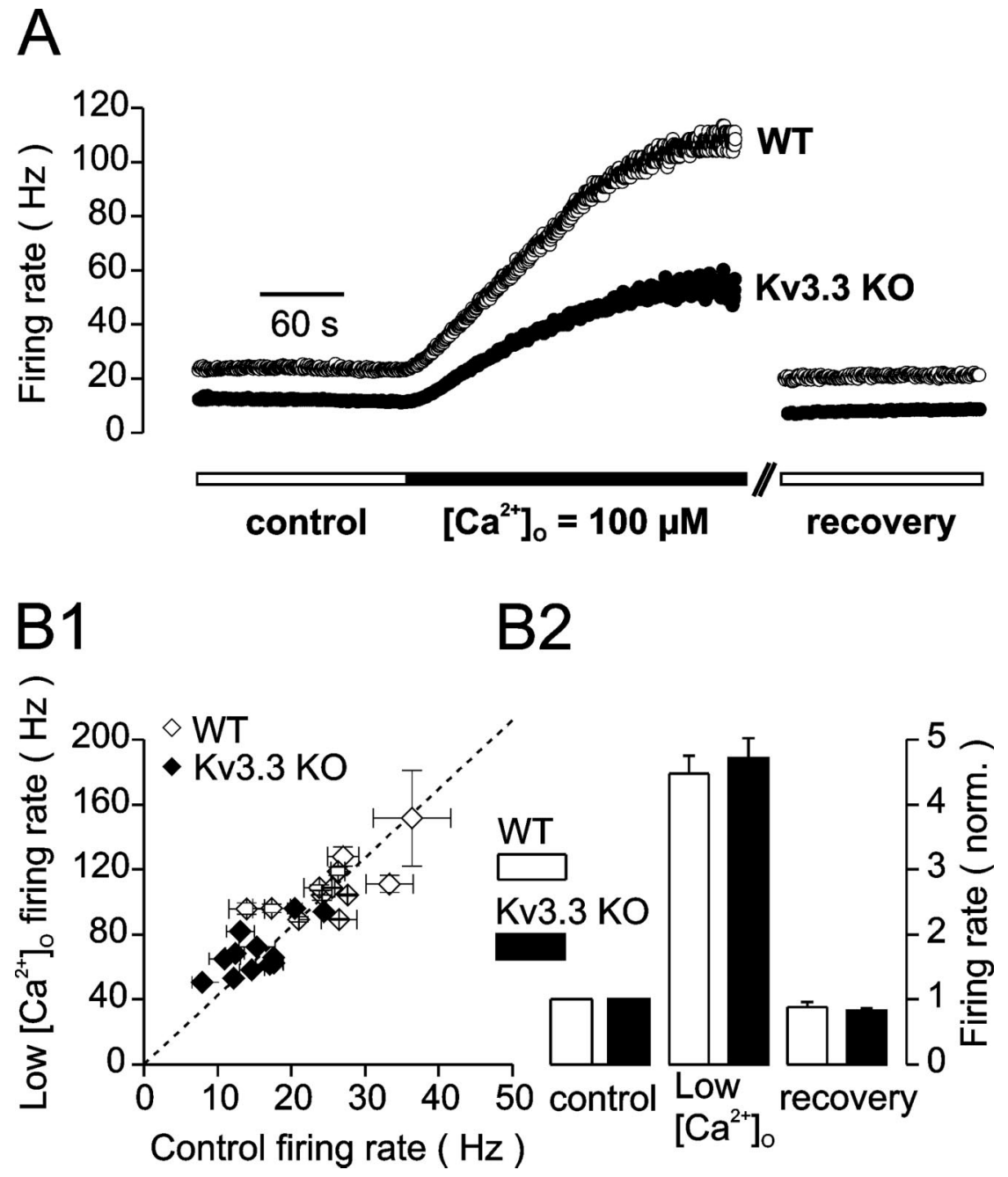

Figure 3. Dependence of spontaneous firing on extracellular $\mathrm{Ca}^{2+}$ concentration in WT and Kv3.3 KO Purkinje neurons. $A$, Rate of spontaneous firing in standard ACSF ([Ca $\left.{ }^{2+}\right]$ of $2 \mathrm{~mm}$; open bar) and during switch to low- $\mathrm{Ca}^{2+} / \mathrm{high}^{-\mathrm{Mg}^{2+}} \mathrm{ACSF}\left(\left[\mathrm{Ca}^{2+}\right]\right.$ of $100 \mu \mathrm{m}$; filled bar). Each data point represents the median of the instantaneous rate of 20 action potentials in a recording from a representative WT (open symbols) and Kv3.3 K0 (filled symbols) Purkinje neuron. B1, Spontaneous firing rate of individual cells in low-Ca ${ }^{2+}$ ACSF plotted versus firing rate in standard ACSF (WT, open symbols; Kv3.3 K0, filled symbols). The rates were determined from the median of the instantaneous spike rate during a $120 \mathrm{~s}$ period in control ACSF (control) and a 60 s period after the firing frequency reached a plateau in low-Ca ${ }^{2+}$ ACSF. The error bars indicate SEMs. B2, Average firing rates and SEMs of WT (12 cells; open columns) and Kv3.3 KO (12 cells; filled columns) after normalization to the baseline rate (control). All solutions contained NBQX $(20 \mu \mathrm{m})$ and picrotoxin $(50 \mu \mathrm{M})$.

A-type potassium current, in Purkinje neurons primarily attributable to the Kv4.3 channel (Sacco and Tempia, 2002), was represented as $n^{4} \times h$ mechanism with rate constants $\left(\right.$ at $22^{\circ} \mathrm{C}$ ) for activation $(n)$

$$
\begin{gathered}
\alpha_{n}(V)=0.15743 \times \exp \left(\frac{V+57}{32.20}\right) \\
\beta_{n}(V)=0.15743 \times \exp \left(-\frac{V+57}{37.51}\right)
\end{gathered}
$$

and inactivation $(h)$

$$
\begin{gathered}
\alpha_{h}(V)=\frac{0.01342}{1+\exp \left(\frac{V+60}{7.86}\right)} \\
\beta_{h}(V)=\frac{0.04477}{1+\exp \left(-\frac{V+54}{11.36}\right)}
\end{gathered}
$$

$V_{1 / 2}$ takes a value of $-28.0 \mathrm{mV}$ for activation and $-68.3 \mathrm{mV}$ for inactivation. The model was adjusted by least-squares fit to measured kinetic data of $\mathrm{K}(\mathrm{A})$ currents in Purkinje neurons (Sacco and Tempia, 2002). Finally, Kv3 current was simulated with a model equivalent to the bKv3 model used in the dynamic-clamp experiment. We also tested a modified bKv3 model featuring a smoothened time course of activation and deactivation (10 $\mu$ s time constant). However, the simulations reported in this work showed no apparent difference between the models. The threshold for bKv3 activation/deactivation, $V_{\mathrm{th}}$, was $-10 \mathrm{mV}$ unless otherwise noted. The potassium reversal potential was set to $-88 \mathrm{mV}$.

(3) The KGR model is based on kinetic data obtained at $22^{\circ} \mathrm{C}$. To simulate the experiments in the present work, we corrected the rate constants in all mechanisms by a temperaturedependent scale factor using $q_{10}=3$. All simulations in this work refer to a temperature of $24^{\circ} \mathrm{C}$.

(4) The maximum conductance, $G_{\max }$, of membrane mechanisms was adjusted to achieve agreement between measured intrinsic spike rates and action potential widths in Kv3.3 KO Purkinje neurons on the one side and simulated data from the model excluding Kv3 on the other side. From the parameter search, we adopted the following values for $G_{\max }$ (in $\mathrm{mS} /$ $\mathrm{cm}^{2}$ ): 16 resurgent $\mathrm{Na}^{+}, 14$ nonresurgent $\mathrm{Na}^{+}, 14 \mathrm{~K}(\mathrm{BK}), 11 \mathrm{Kv} 1,3.9 \mathrm{Kv} 4,0.2 I_{\mathrm{h}}$, and 0.09 leak. The maximum permeability for P-type $\mathrm{Ca}^{2+}$ current was $6 \times 10^{-5} \mathrm{~cm} / \mathrm{s}$. The leak current reversal potential was $-61 \mathrm{mV}$. All other parameters were as given by Khaliq et al. (2003).

(5) Some simulations (see Fig. 9) were performed with the goal to test the contribution of the resurgent $\mathrm{Na}^{+}$current to $\mathrm{Kv3}$-dependent regulation of intrinsic spike output. In these simulations, the blocked state was removed from the resurgent $\mathrm{Na}^{+}$mechanism by decreasing the rate constant for transition into this state to $10^{-12}$ $\mathrm{ms}^{-1}$. All other parameters, including the rate constant of open-state inactivation, remained unchanged.

\section{Results}

Spontaneous activity of Kv3.3-deficient and wild-type Purkinje neurons

We used non-invasive extracellular recordings to measure the spontaneous activity of Purkinje neurons in cerebellar slices prepared from Kv3.3 KO and WT control mice. All measurements were done in ACSF containing $20 \mu \mathrm{M}$ NBQX and $50 \mu \mathrm{M}$ picrotoxin to block synaptic activity. Kv3.3 KO Purkinje neurons generated action potentials at approximately half of the frequency measured in WT cells (Fig. 1A1). Both WT and Kv3.3 KO Purkinje neurons fired regularly as indicated by narrow and single peaked distributions of the instantaneous firing rate (Fig. 1A2). The mean rates were $26.7 \pm 1.2 \mathrm{~Hz}$ for WT Purkinje neurons (61 cells) and $17.8 \pm 0.9 \mathrm{~Hz}$ for Kv3.3 KO Purkinje neurons (52 cells; $p<0.0001)$ at $24 \pm 0.5^{\circ} \mathrm{C}$ (Fig. $\left.1 B\right)$. Linear regression $(R>0.99)$ yielded slope values equivalent to $q_{10}$ values of $2.6 \pm 0.1$ (WT) and $2.9 \pm 0.2(\mathrm{Kv} 3.3 \mathrm{KO})$, demonstrating that the difference between WT and Kv3.3 KO Purkinje neurons was independent of recording temperature in the range of $25-35^{\circ} \mathrm{C}$ (Fig. 1C). 
Shape of spontaneous action potentials of Kv3.3-deficient and wild-type Purkinje neurons

The shape of spontaneously generated action potentials was determined from intracellular current-clamp recordings in Kv3.3 KO (14 cells) and WT (nine cells) Purkinje neurons using zero holding current (Fig. 2). Consistent with the extracellular recordings, WT neurons fired at a higher rate than Kv3.3 KO Purkinje neurons. (WT, $23.3 \pm 2.2 \mathrm{~Hz}$; Kv3.3 KO, $15.6 \pm 1.6 \mathrm{~Hz} ; p=$ 0.007 ). Action potentials rose from the same threshold (evaluated at $10 \mathrm{~ms}$ before the AP peak; WT, $-45.3 \pm 0.8 \mathrm{mV}$; Kv3.3 KO, $-45.2 \pm 0.9 \mathrm{mV}$ ) (Fig. 2A1) but differed significantly in their peak voltage $(\mathrm{WT}, 17.3 \pm 1.8 \mathrm{mV}$; Kv3.3 KO, $30.7 \pm 1.8 \mathrm{mV} ; p<$ 0.0001), amplitude (WT, $62.7 \pm 1.8 \mathrm{mV}$; Kv3.3 KO, $75.9 \pm 2.0$ $\mathrm{mV} ; p<0.001$ ), width (WT, $506 \pm 14 \mu \mathrm{s} ; \mathrm{Kv} 3.3 \mathrm{KO}, 737 \pm 18 \mu \mathrm{s}$; $p<0.0001$ ), and maximum rise slope (WT, $233 \pm 13 \mathrm{mV} / \mathrm{ms}$; Kv3.3 KO, $337 \pm 21 \mathrm{mV} / \mathrm{ms} ; p=0.002$ ) (Fig. $2 A 1, B$ ). Furthermore, the time course of postspike hyperpolarization clearly differed between the two groups (Fig. $2 A 2, B$ ). Notably, the afterhyperpolarization reached slightly (yet statistically not significant) lower voltages in Kv3.3 KO compared with WT Purkinje neurons (WT, $-52.7 \pm 0.8 \mathrm{mV}$; Kv3.3 KO, $-54.3 \pm 0.7 \mathrm{mV} ; p>0.12$ ) but peaked earlier in WT cells $(1.17 \pm 0.05 \mathrm{~ms}$ after AP peak) than Kv3.3 KO cells $(2.55 \pm 0.10 \mathrm{~ms} ; p<0.0001)$ (Fig. $2 A 2, B)$. WT Purkinje neurons were significantly more depolarized than Kv3.3 $\mathrm{KO}$ cells in the time interval from $2 \mathrm{~ms}$ after the AP peak until onset of the next spike. At $20 \mathrm{~ms}$ after AP peak, the average membrane potential was $-47.1 \pm 0.5 \mathrm{mV}$ in WT cells and $-49.0 \pm 0.5$ $\mathrm{mV}$ in Kv3.3 KO cells $(p=0.02)$.

Effect of low extracellular $\mathrm{Ca}^{2+}$ concentration on the rate of Purkinje neuron spontaneous firing

Broader action potentials most likely are associated with an increased influx of $\mathrm{Ca}^{2+}$ and increased activation of $\mathrm{Ca}^{2+}$ activated potassium channels, which in turn regulate the intrinsic firing frequency of Purkinje neurons (Llinas and Sugimori, 1980; Edgerton and Reinhart, 2003). To investigate whether an altered activity of $\mathrm{Ca}^{2+}$-activated potassium channels can account for the decreased firing rate observed in Kv3.3 KO Purkinje neurons, we lowered extracellular $\mathrm{Ca}^{2+}$ concentration to $0.1 \mathrm{~mm}$ and increased extracellular $\mathrm{Mg}^{2+}$ to $2.9 \mathrm{~mm}$. This manipulation increased the firing rate of WT as well as Kv3.3 KO Purkinje neurons (Fig. 3A). Comparison of the firing rates under control conditions and in low $\mathrm{Ca}^{2+}$ (Fig. 3B1,B2) revealed that the firing rate increased by a similar factor $(4.5 \pm 0.3$, WT, 12 cells; $4.7 \pm$ $0.3, \mathrm{KO}, 12$ cells) in WT and Kv3.3 KO Purkinje neurons. Importantly, Kv3.3 KO Purkinje neurons did not reach the firing rates of WT Purkinje cells in low external $\mathrm{Ca}^{2+}(109 \pm 6 \mathrm{~Hz}$, WT, 12 cells; $69 \pm 5 \mathrm{~Hz}, \mathrm{Kv} 3.3 \mathrm{KO}, 12$ cells; $p<0.0001)$. These findings confirmed that the firing rate is dependent on $\mathrm{Ca}^{2+}$ influx and activation of $\mathrm{Ca}^{2+}$-activated potassium channels (Llinas and Sugimori, 1980; Edgerton and Reinhart, 2003) but indicated that the reduced firing rate of Kv3.3 KO Purkinje cells was not caused by an enhanced activity of $\mathrm{Ca}^{2+}$-activated potassium channels.

\section{Rate of spontaneous firing of Purkinje neurons depends on} sodium channel availability

In some cell types, intrinsic oscillatory "pacemaker" potentials that trigger action potential firing are independent from sodium channels activity [that is, they are persistent in tetrodotoxin (TTX), e.g., in olivary neurons (Benardo and Foster, 1986; Llinas and Yarom, 1986; Bal and McCormick, 1997)]. Previous studies have indicated that availability of TTX-sensitive $\mathrm{Na}^{+}$channels, that is the number of channels that are in a closed but neither

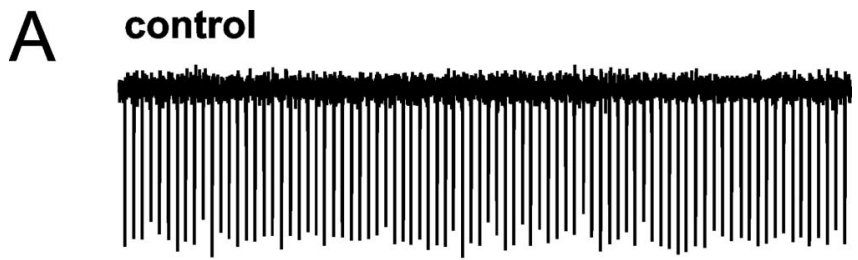

6 nM TTX

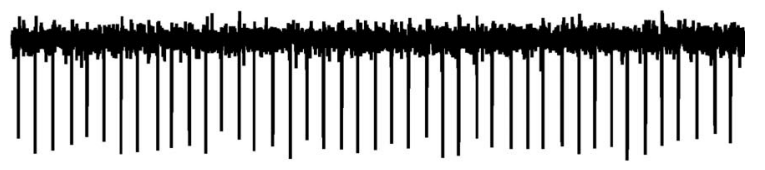

wash out

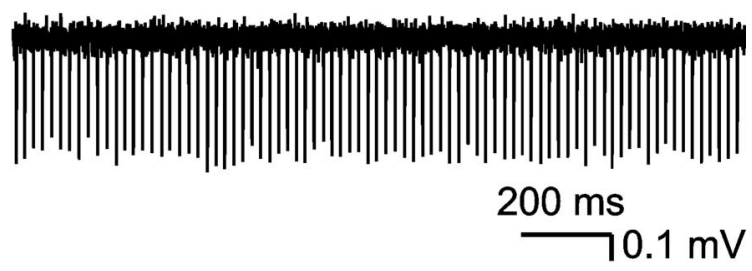

B

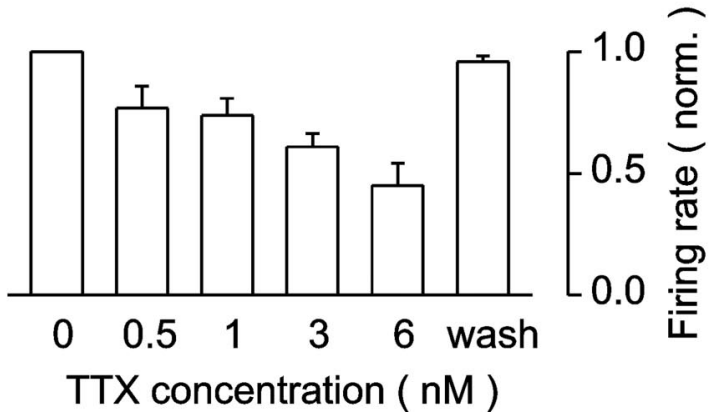

Figure 4. Reduced rate of spontaneous firing in Purkinje neurons under low doses of TTX. $\boldsymbol{A}$ Action potential firing of a WT Purkinje neuron under control conditions, 20 min after application of $6 \mathrm{~nm}$ TTX, and after washout of TTX. $\boldsymbol{B}$, Averaged spike frequency, normalized to control, in the presence of increasing concentrations of $\operatorname{TTX}(0.5,1,3$, and $6 \mathrm{~nm})$. Data are from four cells. Solutions contained NBQX $(20 \mu \mathrm{m})$ and picrotoxin $(50 \mu \mathrm{m})$.

inactivated nor otherwise blocked state, determines the magnitude of a persistent inward current and affects the intrinsic activity of Purkinje neurons (Raman and Bean, 1999; Williams et al., 2002). To confirm that the rate of spontaneous firing depends on the availability of TTX-sensitive sodium channels, we tested the effect of TTX on spontaneous spiking under quasi-stationary conditions at low TTX dose $(<10 \mathrm{nM})$. A decrease in spontaneous spike rate was observed with TTX concentrations as low as $0.5 \mathrm{nM}$ $(23 \pm 9 \%$, four cells) and reached $>50 \%$ ( $55 \pm 10 \%$, four cells; $p=0.02$ ) at $6 \mathrm{~nm}$ TTX (Fig. 4). Control firing rate was restored to $>95 \%$ within $<60 \mathrm{~min}$ after removal of TTX from the external solution.

Dynamic-clamp rescue of the WT firing rate in $\mathrm{Kv} 3.3 \mathrm{KO}$ Purkinje neurons

Alteration in one channel gene may change the expression of other channel genes (Xu et al., 2003; Takahashi and Nagasu, 2005). To investigate whether the decreased firing rate observed in Kv3.3 KO Purkinje neurons can sufficiently be explained by the lack of Kv3.3, we used the dynamic-clamp technique to restore a Kv3-like conductance in Kv3.3 KO Purkinje neurons. In dynamic clamp, current flowing through a simulated ion channel is calculated and injected via the intracellular recording electrode 
A1 Voltage dependency of bKv3 gating

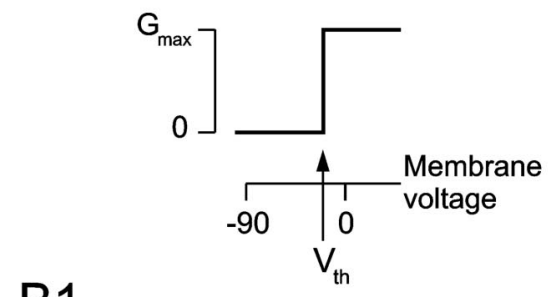

B1
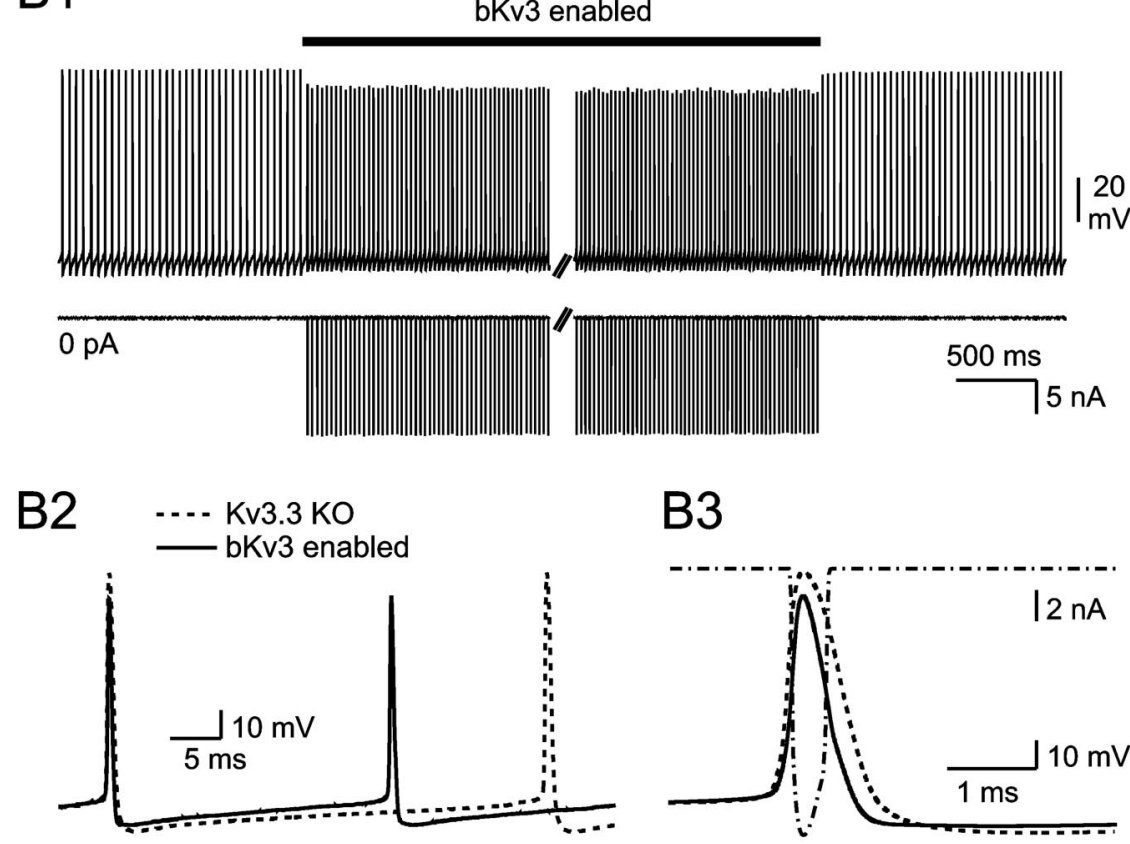

C
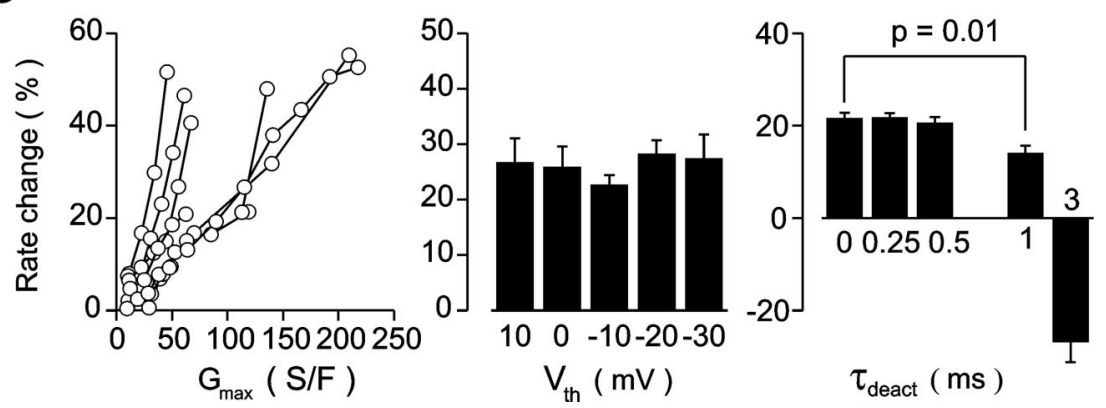

Figure 5. Rescue of the WT firing rate in Kv3.3 KO Purkinje neurons by an artificial Kv3 conductance in dynamic clamp. $\boldsymbol{A 1}$, Conductance-voltage relationship of the Kv3 model (bKv3) used in the dynamic-clamp experiment. The threshold voltage $\left(V_{\text {th }}\right)$ is indicated by an arrow. A2, Schematic illustration of bKv3 conductance during an action potential. B1, Two-electrode dynamicclamp recording with a bKv3 conductance model $\left(G_{\max }=210 \mathrm{~S} / \mathrm{F} ; V_{\text {th }}=-10 \mathrm{mV}\right.$; instantaneous deactivation) applied to a Kv3.3 KO Purkinje cell (zero holding current). Top trace, Membrane voltage recorded with the first electrode. Bottom trace, Current passing through the second electrode. The black horizontal bar indicates the time period when the dynamic-clamp mode was enabled. B2, Traces of two consecutive action potentials during baseline firing (dashed curve) and with the bKv3 conductance enabled (solid curve). The two traces were horizontally aligned at the peak of the first action potential. B3, Action potential shape during baseline firing (dashed curve) and under bKv3 dynamic clamp (solid curve) together with the injected current (dash-dotted curve) at higher temporal resolution. $\boldsymbol{C}$, Left, Shift in spontaneous firing rate as a function of $G_{\max }\left(V_{\text {th }}=-10 \mathrm{mV}\right)$. Data from individual cells are connected by lines (one- and two-electrode recordings). Middle, bKv3-induced change of firing rates obtained with different threshold voltages $V_{\text {th }}\left(G_{\max }=53 \pm 8 \mathrm{~S} / \mathrm{F} ; 9\right.$ cells; one-electrode recordings). Right, Change of firing rate obtained with different deactivation time constants $\tau_{\text {deact }}\left(G_{\max }=73 \pm 22 \mathrm{~S} / \mathrm{F} ; V_{\text {th }}=-10 \mathrm{mV} ; 7\right.$ cells; one-electrode recordings).

into the neuron in real time (update rate of $48 \mathrm{kHz}$ in our recordings). To calculate the open probability of the simulated ion channel, we developed a model (referred to as bKv3) that captures the minimal specific features of ion channels formed by
Kv3.3 subunits (Fig. 5A1,A2). Voltage dependence of activation of bKv3 was modeled as a step function with an activation threshold $V_{\text {th }}$ ranging between -30 and $+10 \mathrm{mV}$. Activation and deactivation time constants $\left(\tau_{\text {act }}\right.$ and $\tau_{\text {deact }}$, respectively) were voltage independent. Activation was quasi-instantaneous (limited only by the response time of the dynamic clamp, $\sim 20 \mu \mathrm{s})$, and deactivation ranged from quasi-instantaneous to $3 \mathrm{~ms}$. Kv3.3 KO Purkinje neurons were allowed to fire at steady state before bKv3 was enabled to generate current (Fig. 5B). Activation of bKv3 caused a switch to higher rates of spontaneous firing [from 24 to $37 \mathrm{~Hz}$ $(+54 \%)$ in the experiment shown in Fig. 5B1-B3]. As expected for a potassium conductance, the dynamic-clamp current for the bKv3 model was negative (outward) at all times (Fig. 5B1, bottom trace). In addition, activation of $\mathrm{bKv} 3$ decreased the action potential amplitude (from 84 to $77 \mathrm{mV}$ ) and the action potential halfwidth (from 630 to $420 \mu \mathrm{s}$ ) (Fig. 5B). We averaged data from individual measurements with $G_{\max }$ values that yielded a spike rate increase of $\sim 50 \%$ [corresponding to the difference in mean spike rates measured between WT $(17.8 \mathrm{~Hz})$ and Kv3.3 KO (26.7 Hz) Purkinje neurons (Fig. 1B)] using instantaneous deactivation of bKv3. Rescue of the WT firing rate in Kv3.3 KO Purkinje neurons (six cells; rescue level, 94-106\%; $G_{\max }=178 \pm 22$ $\mathrm{S} / \mathrm{F}$ ) had the following effect on AP waveform properties: the amplitude of the action potential was decreased by $10 \pm 1 \mathrm{mV}$ (without bKv3, $67 \pm 5 \mathrm{mV}$; bKv3 included, $57 \pm 5 \mathrm{mV} ; p=0.0001$ ) and the half-width by $228 \pm 32 \mu \mathrm{s}$ (without bKv3, $797 \pm 56 \mu$ s; bKv3 included, $570 \pm 52 \mu \mathrm{s}$; $p=0.0008$ ), whereas postspike potentials were more depolarized (without bKv3, $-50 \pm 2 \mathrm{mV}$; bKv3 included, $46 \pm 2 \mathrm{mV}$ at $20 \mathrm{~ms}$ delay from the AP peak; $p=$ 0.02). As expected from the quasiinstantaneous deactivation of $\mathrm{bKv} 3$, the amplitude (without bKv3, $-8.6 \pm 0.8$ $\mathrm{mV}$; bKv3 included, $-7.7 \pm 1.4 \mathrm{mV} ; p>$ 0.4 ) and time (without bKv3, $2.7 \pm 0.1 \mathrm{~ms}$; bKv3 included, $1.9 \pm 0.3 \mathrm{~ms} ; p>0.05$ ) of maximum afterhyperpolarization were not significantly affected by bKv3 current injection.

The bKv3-induced change in intrinsic firing rate increased monotonically (and near to linearly) as a function of bKv 3 conductance $\left(G_{\max }\right)$ up to $200 \mathrm{~S} / \mathrm{F}$ (Fig. $5 C$, left). The change in firing rate did not depend on the bKv3 activation threshold $V_{\text {th }}$ in the range from -30 to $+10 \mathrm{mV}$ (Fig. $5 C$, middle). This is not surprising because variation of $V_{\text {th }}$ within that range translates into a delay of activation of $<150 \mu \mathrm{s}$ (the 
upstroke of the action potential occurred with $>300 \mathrm{mV} / \mathrm{ms}$ at $24^{\circ} \mathrm{C}$ ). A short $\tau_{\text {deact }}$ of bKv3, was, however, a critical parameter. Increase of $\tau_{\text {deact }}$ from quasiinstantaneous to $1 \mathrm{~ms}$ slightly reduced the bKv3-induced change in firing rate (from $21 \pm 2$ to $14 \pm 2 \% ; G_{\max }=53 \pm 8 \mathrm{~S} / \mathrm{F}$; seven cells; $p=0.01$ ). However, bKv3 decreased the rate of spontaneous firing when $\tau_{\text {deact }}$ was increased to $3 \mathrm{~ms}$ (Fig. $5 C$, right). These dynamic-clamp rescue experiments strongly suggest that lack of Kv3.3 current (and not secondary adaptation mechanisms) caused the decrease of spontaneous activity in Kv3.3 KO Purkinje neurons. Furthermore, these experiments validated a simple model of Kv3.3 and specifically identified the fast gating kinetics of the Kv3.3 channel as an essential element in the ionic mechanism of Kv3-dependent regulation of spontaneous activity in Purkinje cells. A more detailed model for Kv3.3 with realistic voltage-dependent activation and deactivation time constants may be required to explain the effects of Kv3.3 on the fast spike afterhyperpolarization. Notwithstanding, the difference in AP shape between WT and Kv3.3 KO Purkinje cells and the results from the dynamic-clamp experiments strongly suggest that the effect of Kv3.3 on firing rate is independent from its contribution to the spike afterhyperpolarization.

\section{Simulation reveals a cooperative effect between $\mathrm{Kv} 3$ and resurgent \\ $\mathrm{Na}^{+}$current}

To investigate how Kv3.3 currents interact with other ion currents during spontaneous firing of Purkinje neurons, we adapted a cell model that was used previously to characterize the contribution of resurgent $\mathrm{Na}^{+}$currents in Purkinje cell spontaneous action potential firing (Khaliq et al., 2003). The model incorporates, into a somatic single compartment, resurgent (Nav1.6) and nonresurgent (Nav1.1/1.2) sodium currents, P-type calcium current, calcium-activated potassium (BK) current, and hyperpolarization-activated mixed cation current $\left(I_{\mathrm{h}}\right)$, with conductances based on established kinetics (Khaliq et al., 2003). Models for potassium channels of the Kv1 and Kv4 type along with the bKv3 model were newly derived (see Materials and Methods). First, we subjected the model to conditions that simulated the experiments as described in Figure 5. Figure 6A1 illustrates spontaneous firing before, during, and after enabling the $\mathrm{bKv} 3$ conductance. As under the experimental condition, the firing rate increased in the presence of bKv3. The reduction of action potential amplitude and increased postspike depolarization seen in the experimental recordings (Fig. $5 B 1, B 2$ ) was replicated in the simulations (Fig. 6A1,A2). Also in agreement with the electrophysiologically recorded data, firing rate increased monotonously with increasing $G_{\max }$ of bKv3 and required fast deactivation kinetics (Figs. $5 C, 6 B, C$ ). The reduction in action

\section{A1 Simulation}

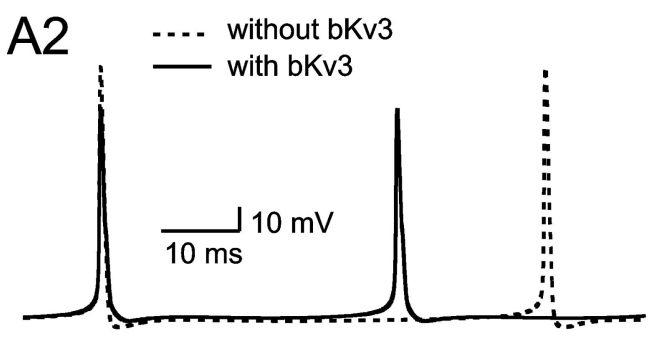

A3

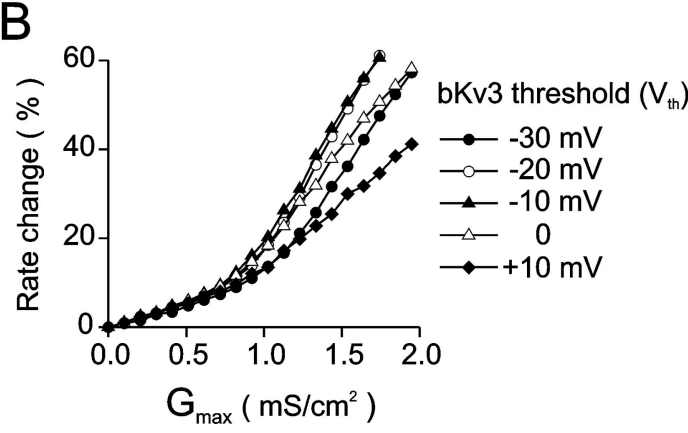

C

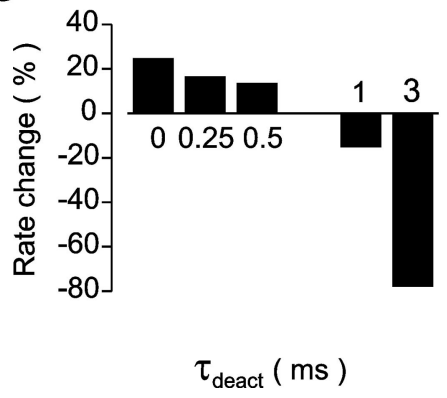

Figure 6. Computational simulation of dynamic-clamp experiments illustrated in Figure 5. A1, Spontaneous action potentials with and without bKv3 conductance $\left(G_{\max }=1.6 \mathrm{mS} / \mathrm{cm}^{2} ; V_{\text {th }}=-10 \mathrm{mV}\right)$. Top trace, Membrane voltage. Bottom trace, bKv Jv3 conductance $\left(G_{\text {max }}\right)$ for threshold voltages from -30 to $+10 \mathrm{mV}$. C, Change of stationary firing rate by a Kv3 model with deactivation constants between 0 and $3 \mathrm{~ms}\left(G_{\max }=1.1 \mathrm{mS} / \mathrm{cm}^{2} ; V_{\text {th }}=-10 \mathrm{mV}\right)$.

potential amplitude and afterhyperpolarization seen in the experimental and the simulation data indicated that the promotion of high-frequency firing by Kv3.3 in Purkinje cells is not simply attributable to facilitation of recovery of $\mathrm{Na}^{+}$channel from inactivation by an enhanced afterhyperpolarization (Rudy and McBain, 2001).

The simulations allowed us to monitor individual ion currents in complete isolation under conditions in which they still dynamically interact. Inspection of currents flowing during steady-state spontaneous firing in the absence and presence of bKv3 revealed that activity of bKv3 led to an enhancement of sodium and potassium current flowing during the interspike interval (Figs. 7, 8). Notably, Nav1.6 current was clearly more affected by bKv3 than Nav1.1/1.2 current. The effect of Kv3 on $\mathrm{Na}^{+}$currents flowing during the interspike interval involved a considerable tonic component that develops during several action potentials after enabling bKv3 (Fig. $8 \mathrm{~A}$ ). Without bKv3, the interspike interval was $55.8 \mathrm{~ms}(17.9 \mathrm{~Hz}$ firing rate; steady state), $51 \mathrm{~ms}$ after one single action potential including bKv3, $32 \mathrm{~ms}$ after 10 APs, and reached a steady-state value of $37 \mathrm{~ms}$ after 40 

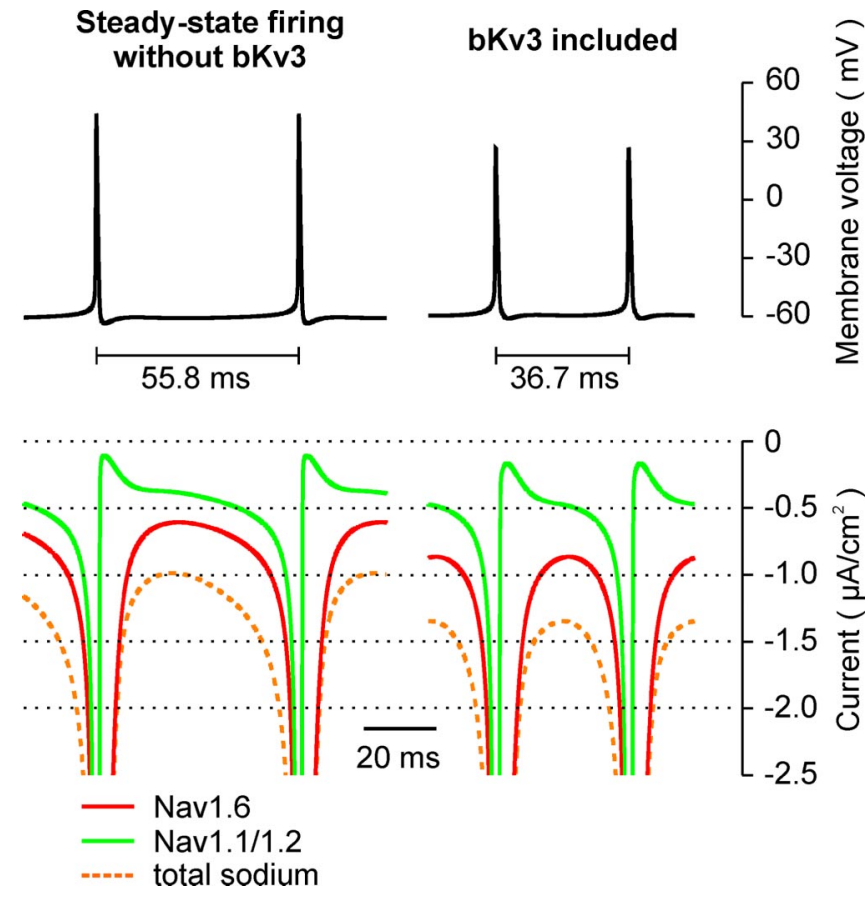

Figure 7. Effect of bKv 3 on $\mathrm{Na}^{+}$currents flowing during the interspike interval. Simulations of steady-state spontaneous firing without (left) and with (right) bKv3 conductance $\left(G_{\max }=\right.$ $\left.1.6 \mathrm{mS} / \mathrm{cm}^{2} ; V_{\text {th }}=-10 \mathrm{mV}\right)$.

APs including bKv3. The development of a Kv3-dependent tonic component is observed in the current amplitude and open probability of Nav1.6 and total potassium conductance, whereas the Nav1.1/1.2 conductance is much less affected by bKv3 activation (Fig. 8A1,A2). The Kv3-induced increase of tonic potassium conductance cannot by itself account for an increase in action potential frequency and is attributable to net depolarization induced by the tonic sodium current. To verify this idea, we performed simulations in which the membrane voltage was clamped (kept constant) after an action potential (Fig. $8 \mathrm{~B}$ ). Under voltage-clamp conditions, the potassium current, with and without bKv3, shows only little time dependence, whereas the $\mathrm{Na}^{+}$current still increased on a timescale matching the interspike interval. Recovery from inactivation of Nav1.1/1.2 clearly contributes to the development of the net sodium current during the interspike interval, but this contribution is exceeded by the tonic Nav1.6 component that develops when bKv3 is enabled.

Together, these observations lead us to hypothesize that bKv3 interacts with properties that are specifically captured in the Nav1.6 model, namely the existence of an open block state that results in a resurgent $\mathrm{Na}^{+}$current (Raman and Bean, 2001; Khaliq et al., 2003). To test this hypothesis, we simulated a cell lacking the blocked state in the Nav1.6 model (Fig. 9). Removal of the blocked state (see Materials and Methods) reduced the rate of spontaneous firing (to $5.0 \mathrm{~Hz}$ in the model without bKv3). We, therefore, used constant current injection into the model without the blocked state to adjust the firing rate so that (in simulations without bKv3) the same spike rates were obtained in models with/without the blocked state (Fig. 9, left). In the absence of the blocked state, bKv3 had a much weaker effect on the stationary firing rate $(6.7 \%$ rate change vs $52 \%$ rate change in the control model including the Nav1.6 blocked state) (Fig. 9). Moreover, magnitude and time course of currents flowing during the interspike interval were no longer significantly influenced by the presence or absence of bKv3. This set of simulations demonstrated a specific cooperation between $\mathrm{Kv} 3$ type of potassium currents and resurgent $\mathrm{Na}^{+}$currents.

\section{Discussion}

Genetic knock-out of Kv3.3 potassium channels led to a reduction in the rate of intrinsic action potential firing in Purkinje neurons. Dynamic-clamp rescue experiments demonstrated a causal relationship between a reduction in firing rate and the lack of Kv3.3 currents. Computer simulation experiments revealed that currents mediated by Kv3.3 channels interact with the kinetics of $\mathrm{Na}^{+}$currents, leading to the development of a tonic inward $\mathrm{Na}^{+}$current. This effect of Kv3.3 required the open block mechanism that produces resurgent $\mathrm{Na}^{+}$currents.

\section{Contribution of Kv3.3 currents in the generation of Purkinje} neuron action potential waveform

Of the four genes comprising the Kv3 family (Kv3.1, Kv3.2, Kv3.3, and Kv3.4) (Rudy and McBain, 2001), Purkinje cells express high levels of Kv3.3 and lower levels of Kv3.4 in the cell body and dendrites, whereas Kv3.1 and Kv3.2 subunits are not expressed at functionally relevant levels (Weiser et al., 1994; Martina et al., 2003; McMahon et al., 2004). Channels from Kv3 units acquire their unique properties from the combination of a high threshold of activation (more positive than $-20 \mathrm{mV}$ ) and very fast activation and deactivation kinetics. Thus, Kv3 channels are activated transiently during action potential discharge, contribute only to the fast component of action potential afterhyperpolarization, and remain inactive during interspike periods (Rudy and McBain, 2001). Consistent with these properties, absence of Kv3.3 in Purkinje neurons leads to broadened APs that are larger in amplitude and that exhibit a delayed but not reduced action potential afterhyperpolarization (Fig. 2) (McMahon et al., 2004). The action potential afterhyperpolarization of Kv3.3 KO Purkinje neurons likely reflects activity of BK-type potassium currents [mediated by $\mathrm{K}(\mathrm{Ca}) 1.1$ channels] that activate during the late repolarization phase of the action potential (Womack and Khodakhah, 2002; Sausbier et al., 2004).

\section{Significance of Kv3.3 for the control of spontaneous activity of Purkinje neurons}

Kv3 potassium channels have been recognized to facilitate highfrequency repetitive firing (Rudy et al., 1999; Rudy and McBain, 2001). This surmise was originally derived from kinetic data that indicated that Kv3 currents activate specifically during action potential repolarization and, thereby, accelerate the recovery from inactivation of sodium channels without compromising the amplitude of action potentials. Voltage-clamp experiments in HEK human embryonic kidney cells using an action potential waveform (Rudy et al., 1999) and dynamic-clamp experiments in hippocampal interneurons (Lien and Jonas, 2003) supported this idea and demonstrated that spiking induced by direct current injection is facilitated by Kv3-type conductances. The model channel used in the dynamic-clamp experiments by Lien and Jonas (2003) required a delayed activation did not affect action potential amplitude and promoted a fast spike afterhyperpolarization. Their results are therefore in full agreement with the "facilitated recovery from inactivation model."

The mechanisms underlying spontaneous action potential firing differs from current-evoked action potential generation. Induction of action potentials from subthreshold holding potentials recruits ionic currents that are partially inactivated, deactivated, or in an open block state (Na1.6) during normal spontaneous firing. Furthermore, action potentials may be gen- 
erated by the same set of ionic currents that are active during interspike intervals and that control the firing rate. Therefore, one may expect that the role of $\mathrm{Kv} 3$ channels in spontaneously firing neurons differs from the "facilitated recovery from inactivation model." Indeed, action potentials are larger and spike afterhyperpolarization is not reduced in $\mathrm{Kv} 3.3 \mathrm{KO}$ Purkinje neurons (Fig. 2). Moreover, the time constant of recovery of Purkinje cell sodium currents from inactivation is fast compared with the interspike interval (even in the absence of a pronounced spike afterhyperpolarization) and, therefore, is not likely to be the main parameter determining the intrinsic rate of Purkinje neuron action potential firing (Fig. 7). These observations along with the finding that spontaneous firing is reduced in Kv3.3 KO Purkinje neurons prompted us to investigate the role of a Kv3 model conductance in dynamic-clamp and wholecell simulation experiment. The dynamicclamp experiments (Fig. 5) and simulations results (Fig. 6) confirmed that activity of $\mathrm{Kv} 3.3$ reduces the action potential amplitude and amplitude of spike afterhyperpolarization. Inspection of ion currents flowing during spontaneous action potential firing in the absence and presence of bKv3 current revealed a close kinetic interaction between $\mathrm{Kv} 3$ and resurgent $\mathrm{Na}^{+}$currents, leading to enhanced activation of interspike sodium current (Figs. 7, 8). Previous studies by Raman and Bean (1999) in acutely dissociated cell bodies of mouse Purkinje neurons led to a similar conclusion, namely that the spontaneous firing of Purkinje neuron cell bodies depends mainly on tetrodotoxin-sensitive sodium current flowing between spikes, whereas the high firing rate is promoted by large potassium currents that repolarize the cell rapidly and deactivate quickly.

A subthreshold, non-inactivating current carried by sodium (persistent $\mathrm{Na}^{+}$current) was first described in Purkinje neurons (Llinas and Sugimori, 1980; Vega-Saenz de Miera et al., 1997; Kay et al., 1998) and subsequently in many other cell types. In Purkinje cells, this persistent $\mathrm{Na}^{+}$current most likely corresponds to the component of the Nav1.6 current that flows between spontaneous action potentials and that is a consequence of the open channel block during peak depolarization (Raman and Bean, 1997). The dynamic regulation of Nav1.6-mediated current by $\mathrm{Kv} 3$, as described in this work, cannot be reduced to the kinetics of the isolated currents, and this may explain the difficulties in previous characterization and interpretation of persistent $\mathrm{Na}^{+}$ currents of Purkinje neurons (Kay et al., 1998).

Purkinje neurons express Nav1.1, Nav1.2, and Nav1.6 $\alpha$ subunits (Shah et al., 2001; Chung et al., 2003; Schaller and Caldwell, 2003). Resurgent $\mathrm{Na}^{+}$currents have been associated with Nav1.6 because these subunits form channels in Purkinje neurons that have an open-state block and because resurgent sodium current in Purkinje neurons is diminished in Nav1.6-deficient mice (Raman et al., 1997). Compared with Nav1.1/1.2, the Nav1.6 channel has slower inactivation kinetics, which increases the efficiency of open channel block (Grieco and Raman, 2004). However, resurgent sodium currents can also be generated by other subunits, for instance if interaction with $\beta$ subunits results in an open channel block-like state (Do and Bean, 2003, 2004; Grieco et al., 2005). The simulated Nav1.6 currents may, therefore, in other cells, correspond to kinetic schemes that are biologically implemented by channel proteins other than Nav1.6.

BK channels show negligible activity during interspike periods (Womack and Khodakhah, 2002), and iberiotoxin block of the BK channel had no significant effect on the spontaneous spiking activity of Purkinje cells (Edgerton and Reinhart, 2003). In agreement with these data, Purkinje cell spiking rate was only weakly dependent on BK channel conductance (standard model with BK included, $27.2 \mathrm{~Hz}$; without $\mathrm{BK}, 33.5 \mathrm{~Hz}$ ) in our simulations. This most likely reflects the slower kinetics of the BK channel compared with the Kv3.3 channel. In fact, prolonging Kv3 activity (by 
without bKv3

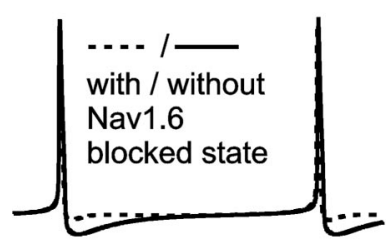

$55.8 \mathrm{~ms}$

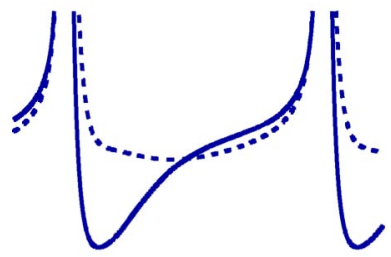

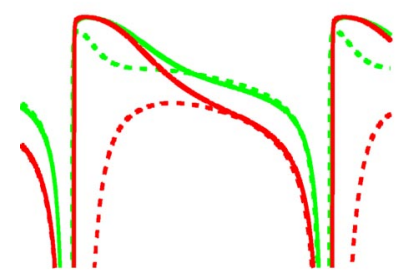

-..-1- Nav1:6

-..- I- Nav1.1/1.2

.... 1 - total potassium

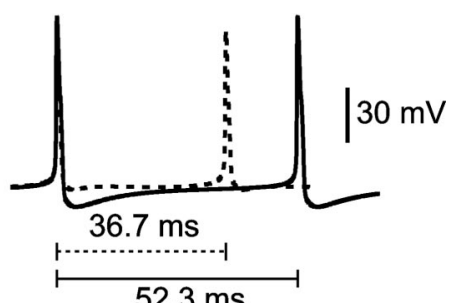

Figure 9. Role of the blocked state of Nav1.6 in Kv3-dependent intrinsic activity. Simulations without (left) and with (right) bKv3 conductance $\left(G_{\max }=1.6 \mathrm{mS} / \mathrm{cm}^{2} ; V_{\mathrm{th}}=-10 \mathrm{mV}\right)$ in the presence (dashed traces) and absence (solid traces) of a blocked state in the Nav1.6 model. At the top are voltage transients with the interspike interval represented by horizontal lines. The bottom shows ionic currents as indicated in the legend. The simulations without blocked state in the Nav1.6 model included a $32 \mathrm{nA} / \mathrm{cm}^{2}$ holding current.

increasing the time constant of deactivation of bKv3) (Figs. 5C, $6 C$ ) degraded the function of the bKv3 channel to facilitate highfrequency spontaneous spikes. The functional differentiation between BK- and Kv3-type currents underscores the importance of fast deactivation kinetics as an essential functional property of the $\mathrm{Kv} 3$ channel in the regulation of spontaneous activity of Purkinje cells.

\section{Functional implications}

Purkinje neurons are spontaneously active in vivo and in vitro (Granit and Phillips, 1956; Armstrong and Rawson, 1979; Llinas and Sugimori, 1980; Häusser and Clark, 1997). On average, their basal firing rates are $\sim 40 \mathrm{~Hz}$, but rates vary greatly between individual cells in vivo (Granit and Phillips, 1956; Armstrong and Rawson, 1979). The rate of spontaneous firing of Purkinje neurons is plastic and depends on the history of parallel fiber and climbing fiber activity (Smith and Otis, 2003; Cerminara and Rawson, 2004). Upregulation and downregulation of firing rates provides bidirectional inhibitory control of their target neurons in the deep cerebellar nuclei. Understanding of the ionic mechanisms determining the rate of spontaneous firing will help to clarify the molecular basis underlying firing rate plasticity. In this context, it is notable that Kv3.1 channels are well known to be regulated at both the transcriptional and posttranslation levels (Atzori et al., 2000; Behnisch et al., 2004; von Hehn et al., 2004; Itri et al., 2005; Song et al., 2005). At present, it is not known whether Kv3.3 channels are subject to similar regulatory mecha- nisms. Reduced intrinsic firing rates of Purkinje neurons in both Kv3.3 KO and Nav1.6 KO mice correlate with deficits in motor execution (Kohrman et al., 1996; Matsukawa et al., 2003; McMahon et al., 2004; Joho et al., 2006). This underlines the functional significance of spontaneous activity of Purkinje cells in cerebellar function.

\section{References}

Armstrong DM, Rawson JA (1979) Activity patterns of cerebellar cortical neurons and climbing fibre afferents in the awake cat. J Physiol (Lond) 289:425-448.

Atzori M, Lau D, Tansey EP, Chow A, Ozaita A, Rudy B, McBain CJ (2000) $\mathrm{H} 2$ histamine receptor-phosphorylation of Kv3.2 modulates interneuron fast spiking. Nat Neurosci 3:791-798.

Bal T, McCormick DA (1997) Synchronized oscillations in the inferior olive are controlled by the hyperpolarization-activated cation current $\mathrm{I}(\mathrm{h})$. J Neurophysiol 77:3145-3156.

Behnisch T, Matsushita S, Knöpfel T (2004) Imaging of gene expression during long-term potentiation. NeuroReport 15:2039-2043.

Benardo LS, Foster RE (1986) Oscillatory behavior in inferior olive neurons: mechanism, modulation, cell aggregates. Brain Res Bull 17:773-784.

Cerminara NL, Rawson JA (2004) Evidence that climbing fibers control an intrinsic spike generator in cerebellar Purkinje cells. J Neurosci 24:4510-4517.

Chan E (1997) Regulation and function of Kv3.3. PhD thesis, Rockefeller University.

Chung YH, Joo KM, Kim MJ, Cha CI (2003) Age-related changes in the distribution of $\mathrm{Na}(\mathrm{v}) 1.1$ and $\mathrm{Na}(\mathrm{v}) 1.2$ in rat cerebellum. NeuroReport 14:841-845.

Do MT, Bean BP (2003) Subthreshold sodium currents and pacemaking of subthalamic neurons: modulation by slow inactivation. Neuron 39:109-120.

Do MT, Bean BP (2004) Sodium currents in subthalamic nucleus neurons from Nav1.6-null mice. J Neurophysiol 92:726-733.

Edgerton JR, Reinhart PH (2003) Distinct contributions of small and large conductance $\mathrm{Ca}^{2+}$-activated $\mathrm{K}^{+}$channels to rat Purkinje neuron function. J Physiol (Lond) 548:53-69.

Erisir A, Lau D, Rudy B, Leonard CS (1999) Function of specific K ${ }^{+}$channels in sustained high-frequency firing of fast-spiking neocortical interneurons. J Neurophysiol 82:2476-2489.

Goldman-Wohl DS, Chan E, Baird D, Heintz N (1994) Kv3.3b: a novel Shaw type potassium channel expressed in terminally differentiated cerebellar Purkinje cells and deep cerebellar nuclei. J Neurosci 14:511-522.

Granit R, Phillips CG (1956) Excitatory and inhibitory processes acting upon individual Purkinje cells of the cerebellum in cats. J Physiol (Lond) 133:520-547.

Grieco TM, Raman IM (2004) Production of resurgent current in NaV1.6null Purkinje neurons by slowing sodium channel inactivation with $\beta$-pompilidotoxin. J Neurosci 24:35-42.

Grieco TM, Malhotra JD, Chen C, Isom LL, Raman IM (2005) Openchannel block by the cytoplasmic tail of sodium channel beta 4 as a mechanism for resurgent sodium current. Neuron 45:233-244.

Häusser M, Clark BA (1997) Tonic synaptic inhibition modulates neuronal output pattern and spatiotemporal synaptic integration. Neuron 19:665-678.

Häusser M, Raman IM, Otis T, Smith SL, Nelson A, du Lac S, Loewenstein Y, Mahon S, Pennartz C, Cohen I, Yarom Y (2004) The beat goes on: spontaneous firing in mammalian neuronal microcircuits. J Neurosci 24:9215-9219.

Hines ML, Carnevale NT (1997) The NEURON simulation environment. Neural Comput 9:1179-1209.

Itri JN, Michel S, Vansteensel MJ, Meijer JH, Colwell CS (2005) Fast delayed rectifier potassium current is required for circadian neural activity. Nat Neurosci 8:650-656.

Joho RH, Street C, Matsushita S, Knöpfel T (2006) Behavioral motor dysfunction in Kv3-type potassium channel-deficient mice. Genes Brain Behav, in press.

Kay AR, Sugimori M, Llinas R (1998) Kinetic and stochastic properties of a persistent sodium current in mature guinea pig cerebellar Purkinje cells. J Neurophysiol 80:1167-1179.

Khaliq ZM, Gouwens NW, Raman IM (2003) The contribution of resurgent 
sodium current to high-frequency firing in Purkinje neurons: an experimental and modeling study. J Neurosci 23:4899-4912.

Kohrman DC, Smith MR, Goldin AL, Harris J, Meisler MH (1996) A missense mutation in the sodium channel Scn8a is responsible for cerebellar ataxia in the mouse mutant jolting. J Neurosci 16:5993-5999.

Kullmann PH, Wheeler DW, Beacom J, Horn JP (2004) Implementation of a fast 16-bit dynamic clamp using LabVIEW-RT. J Neurophysiol 91:542-554.

Lien CC, Jonas P (2003) Kv3 potassium conductance is necessary and kinetically optimized for high-frequency action potential generation in hippocampal interneurons. J Neurosci 23:2058-2068.

Llinas R, Sugimori M (1980) Electrophysiological properties of in vitro Purkinje cell somata in mammalian cerebellar slices. J Physiol (Lond) 305:171-195.

Llinas R, Yarom Y (1986) Oscillatory properties of guinea-pig inferior olivary neurones and their pharmacological modulation: an in vitro study. J Physiol (Lond) 376:163-182.

Martina M, Yao GL, Bean BP (2003) Properties and functional role of voltage-dependent potassium channels in dendrites of rat cerebellar Purkinje neurons. J Neurosci 23:5698-5707.

Matsukawa H, Wolf AM, Matsushita S, Joho RH, Knöpfel T (2003) Motor dysfunction and altered synaptic transmission at the parallel fiber-Purkinje cell synapse in mice lacking potassium channels Kv3.1 and Kv3.3. J Neurosci 23:7677-7684.

McKay BE, Turner RW (2004) Kv3 $\mathrm{K}^{+}$channels enable burst output in rat cerebellar Purkinje cells. Eur J Neurosci 20:729-739.

McKay BE, Molineux ML, Mehaffey WH, Turner RW (2005) Kv1 K ${ }^{+}$channels control Purkinje cell output to facilitate postsynaptic rebound discharge in deep cerebellar neurons. J Neurosci 25:1481-1492.

McMahon A, Fowler SC, Perney TM, Akemann W, Knöpfel T, Joho RH (2004) Allele-dependent changes of olivocerebellar circuit properties in the absence of the voltage-gated potassium channels Kv3.1 and Kv3.3. Eur J Neurosci 19:3317-3327.

Nelson AB, Krispel CM, Sekirnjak C, du LS (2003) Long-lasting increases in intrinsic excitability triggered by inhibition. Neuron 40:609-620.

Raman IM, Bean BP (1997) Resurgent sodium current and action potential formation in dissociated cerebellar Purkinje neurons. J Neurosci 17:4517-4526.

Raman IM, Bean BP (1999) Ionic currents underlying spontaneous action potentials in isolated cerebellar Purkinje neurons. J Neurosci 19:1663-1674.

Raman IM, Bean BP (2001) Inactivation and recovery of sodium currents in cerebellar Purkinje neurons: evidence for two mechanisms. Biophys J 80:729-737.

Raman IM, Sprunger LK, Meisler MH, Bean BP (1997) Altered subthreshold sodium currents and disrupted firing patterns in Purkinje neurons of Scn8a mutant mice. Neuron 19:881-891.

Rudy B, McBain CJ (2001) Kv3 channels: voltage-gated $\mathrm{K}^{+}$channels designed for high-frequency repetitive firing. Trends Neurosci 24:517-526.

Rudy B, Chow A, Lau D, Amarillo Y, Ozaita A, Saganich M, Moreno H, Nadal
MS, Hernandez-Pineda R, Hernandez-Cruz A, Erisir A, Leonard C, VegaSaenz dM (1999) Contributions of Kv3 channels to neuronal excitability. Ann NY Acad Sci 868:304-343.

Sacco T, Tempia F (2002) A-type potassium currents active at subthreshold potentials in mouse cerebellar Purkinje cells. J Physiol (Lond) 543:505-520.

Sausbier M, Hu H, Arntz C, Feil S, Kamm S, Adelsberger H, Sausbier U, Sailer CA, Feil R, Hofmann F, Korth M, Shipston MJ, Knaus HG, Wolfer DP, Pedroarena CM, Storm JF, Ruth P (2004) Cerebellar ataxia and Purkinje cell dysfunction caused by $\mathrm{Ca}^{2+}$-activated $\mathrm{K}^{+}$channel deficiency. Proc Natl Acad Sci USA 101:9474-9478.

Schaller KL, Caldwell JH (2003) Expression and distribution of voltagegated sodium channels in the cerebellum. Cerebellum 2:2-9.

Shah BS, Stevens EB, Pinnock RD, Dixon AK, Lee K (2001) Developmental expression of the novel voltage-gated sodium channel auxiliary subunit beta3, in rat CNS. J Physiol (Lond) 534:763-776.

Smith SL, Otis TS (2003) Persistent changes in spontaneous firing of Purkinje neurons triggered by the nitric oxide signaling cascade. J Neurosci 23:367-372.

Song P, Yang Y, Barnes-Davies M, Bhattacharjee A, Hamann M, Forsythe ID, Oliver DL, Kaczmarek LK (2005) Acoustic environment determines phosphorylation state of the Kv3.1 potassium channel in auditory neurons. Nat Neurosci 8:1335-1342.

Takahashi E, Nagasu T (2005) Pattern of compensatory expression of voltage-dependent $\mathrm{Ca}^{2+}$ channel alphal and beta subunits in brain of $\mathrm{N}$-type $\mathrm{Ca}^{2+}$ channel alpha1B subunit gene-deficient mice with a CBA/JN genetic background. Exp Anim 54:29-36.

Vega-Saenz de Miera EC, Rudy B, Sugimori M, Llinas R (1997) Molecular characterization of the sodium channel subunits expressed in mammalian cerebellar Purkinje cells. Proc Natl Acad Sci USA 94:7059-7064.

von Hehn CA, Bhattacharjee A, Kaczmarek LK (2004) Loss of Kv3.1 tonotopicity and alterations in cAMP response element-binding protein signaling in central auditory neurons of hearing impaired mice. J Neurosci 24:1936-1940.

Weiser M, Vega-Saenz de Miera E, Kentros C, Moreno H, Franzen L, Hillman D, Baker H, Rudy B (1994) Differential expression of Shaw-related $\mathrm{K}^{+}$ channels in the rat central nervous system. J Neurosci 14:949-972.

Williams SR, Christensen SR, Stuart GJ, Häusser M (2002) Membrane potential bistability is controlled by the hyperpolarization-activated current $\mathrm{I}(\mathrm{H})$ in rat cerebellar Purkinje neurons in vitro. J Physiol (Lond) 539:469-483.

Womack MD, Khodakhah K (2002) Characterization of large conductance $\mathrm{Ca}^{2+}$-activated $\mathrm{K}^{+}$channels in cerebellar Purkinje neurons. Eur J Neurosci 16:1214-1222.

Xu M, Welling A, Paparisto S, Hofmann F, Klugbauer N (2003) Enhanced expression of L-type Cav1.3 calcium channels in murine embryonic hearts from Cav1.2-deficient mice. J Biol Chem 278:40837-40841.

Zerr P, Adelman JP, Maylie J (1998) Episodic ataxia mutations in Kv1.1 alter potassium channel function by dominant negative effects or haploinsufficiency. J Neurosci 18:2842-2848. 